AperTO - Archivio Istituzionale Open Access dell'Università di Torino

\title{
Modelling photochemical transformation of emerging organic pollutants in surface waters: effect of water level fluctuations following outflow or evaporation, relevant to arid and semi-arid environments
}

This is the author's manuscript

Original Citation:

\section{Availability:}

This version is available http://hdl.handle.net/2318/141146

since 2016-10-10T13:04:04Z

Published version:

DOI:10.1080/03067319.2013.803284

Terms of use:

Open Access

Anyone can freely access the full text of works made available as "Open Access". Works made available under a Creative Commons license can be used according to the terms and conditions of said license. Use of all other works requires consent of the right holder (author or publisher) if not exempted from copyright protection by the applicable law. 


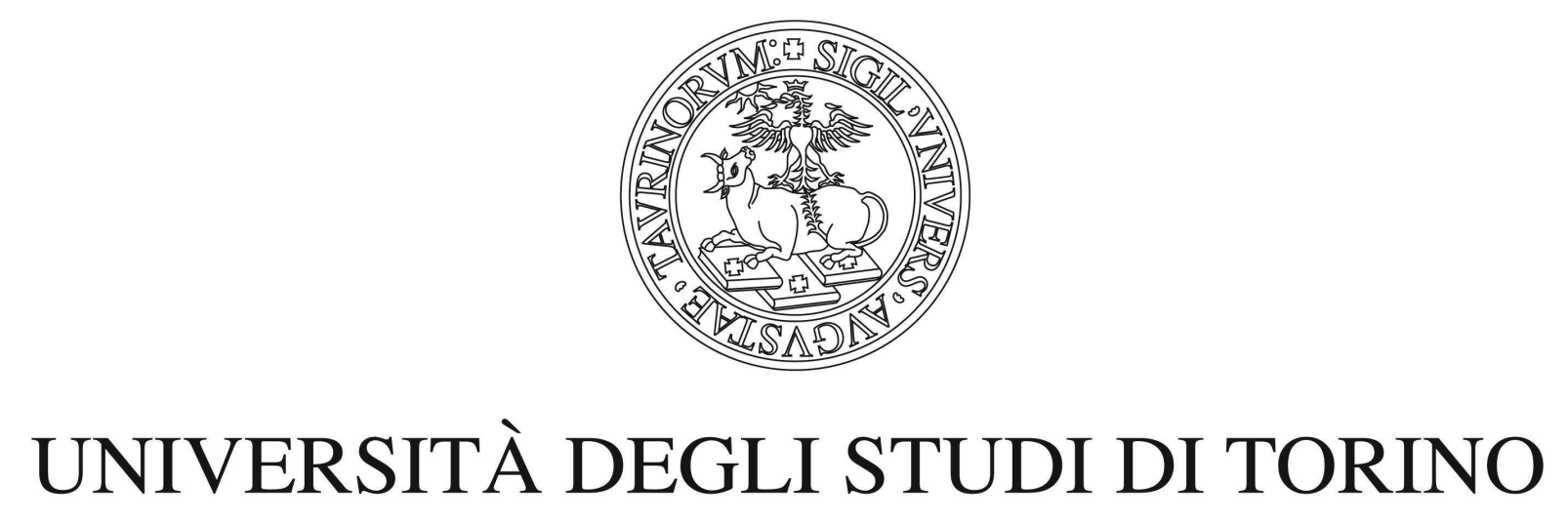

This is an author version of the contribution published on:

Questa è la versione dell'autore dell'opera:

M. Minella, V. Maurino, C. Minero, D. Vione. Modelling photochemical transformation of emerging organic pollutants in surface waters: Effect of water level fluctuations following outflow or evaporation. Intern. J. Environ. Anal. Chem. 2013, 93, 1698-1717. DOI: 10.1080/03067319.2013.803284.

\section{The definitive version is available at:}

La versione definitiva è disponibile alla URL:

M. Minella, V. Maurino, C. Minero, D. Vione. Modelling photochemical transformation of emerging organic pollutants in surface waters: Effect of water level fluctuations following outflow or evaporation. Intern. J. Environ. Anal. Chem. 2013, 93, 1698-1717. DOI: 10.1080/03067319.2013.803284.

(http://www.tandfonline.com) 


\title{
Modelling photochemical transformation of emerging organic pollutants in surface waters: Effect of water level fluctuations following outflow or evaporation
}

\author{
Marco Minella $^{a}$, Valter Maurino $^{a}$, Claudio Minero $^{a}$ and Davide Vione $^{\mathrm{ab}_{*}}$ \\ ${ }^{a}$ Università degli Studi di Torino, Dipartimento di Chimica, Via P. Giuria 5, 10125 Torino, Italy. \\ http://www.chimicadellambiente.unito.it \\ ${ }^{b}$ Università degli Studi di Torino, Centro Interdipartimentale NatRisk, Via Leonardo da Vinci 44, \\ 10095 Grugliasco (TO), Italy. http://www.natrisk.org
}

* Corresponding author. Tel. +39-011-6705296; Fax +39-011-6707615; E-mail: davide.vione@unito.it

\begin{abstract}
Water bodies located in arid and semi-arid environments undergo important fluctuations of the water level, and in the dry season water loss may occur through phenomena such as outflow and evaporation. Water scarcity often exacerbates the impact of pollution, because harmful compounds can reach very high concentration values in the presence of relatively low water volumes. Among self-cleansing (depollution) processes of water bodies, photochemical reactions are expected to play an important role in pollutant attenuation, although sometimes they yield harmful intermediates. In this work, the effects of water-level fluctuations on photochemical reactions were studied by means of a modelling approach. We investigated how water outflow and evaporation (as well as a mixed scenario) might modify steady-state concentrations of the most important reactive transients involved in photoinduced transformation $\left({ }^{\bullet} \mathrm{OH}, \mathrm{CO}_{3}{ }^{-\bullet},{ }^{1} \mathrm{O}_{2}\right.$ and triplet states of chromophoric dissolved organic matter, $\left.{ }^{3} \mathrm{CDOM}^{*}\right)$. Under the same conditions, it was also assessed the possible phototransformation of emerging pollutants such as carbamazepine, ibuprofen, 2,4-dichloro-6nitrophenol and 2,4-dinitrophenol. Model results suggest that water loss processes would generally enhance photochemical reactions, but to a variable extent depending on the particular pathway under consideration. Outflow would favour all photochemical reactions, and particularly those involving ${ }^{\bullet} \mathrm{OH}$ and $\mathrm{CO}_{3}{ }^{-\bullet}$. Conversely, evaporation would enhance reaction with ${ }^{1} \mathrm{O}_{2}$ and ${ }^{3} \mathrm{CDOM}^{*}$ while having practically no effect on ${ }^{\circ} \mathrm{OH}, \mathrm{CO}_{3}^{-\bullet}$ and direct photolysis. Enhancement of photochemical self-cleansing of water bodies would partially reduce the pollution impact, but in some cases sunlight-induced processes could generate harmful compounds.
\end{abstract}

Keywords: Ephemeral lakes; Environmental photochemistry; Photochemical depollution; Emerging organic pollutants; Photoinduced transformation; Environmental modelling; Water scarcity. 


\section{Introduction}

Water availability is becoming an increasingly important problem in many areas of the world [1,2]. A further matter of concern is represented by climate change, which is dangerously shifting the area of water scarcity from traditionally arid sub-tropical and tropical zones to temperate ones. For instance, almost all the Mediterranean area is potentially at risk for a possible reduction of water availability [3-6]. Water scarcity presents the additional problem of exacerbating the effects of pollution. In fact, pollutant emission can cause high concentration values in the receiving water body, if water volume is limited [7-9]. For the same reason, the environmental impact of agricultural activities (e.g. pesticides) or of urban wastewater (containing many emerging pollutants such as pharmaceuticals) on aquatic environments is higher under conditions of water scarcity [10,11]. Rainfall in arid and semi-arid regions is limited overall but it is often concentrated in a few major events. Therefore, a typical consequence of water scarcity is the considerable seasonal fluctuation of the level of surface water bodies, sometimes up to complete desiccation during the dry season [12-14].

Chemical transformation is one of the processes that limit the concentration of pollutants in environmental waters. Photochemical reactions are a very important class of abiotic pathways leading to pollutant degradation, thereby attenuating pollution but sometimes also producing harmful intermediates [15]. Light-induced reactions are usually classified as direct photolysis (where sunlight absorption by the pollutant causes its transformation) and indirect or sensitised photoreactions. In the latter case, radiation absorption by photoactive compounds (e.g. nitrate, nitrite and chromophoric dissolved organic matter, CDOM) induces the generation of reactive transients (most notably ${ }^{\circ} \mathrm{OH},{ }^{1} \mathrm{O}_{2}$ and ${ }^{3} \mathrm{CDOM}^{*}$ ) that promote transformation of dissolved compounds including organic pollutants $[16,17]$. An additional transient, $\mathrm{CO}_{3}{ }^{-}$, is produced by oxidation of carbonate and/or bicarbonate by ${ }^{\circ} \mathrm{OH}$ and ${ }^{3} \mathrm{CDOM}^{*}[18]$.

All photochemical processes can induce pollutant transformation, but there is evidence that ${ }^{\circ} \mathrm{OH}$ is a bit less likely to yield harmful intermediates compared to other photoinduced transients or to direct photolysis [19]. Photochemical reactions are strongly affected by irradiance, water chemistry and water depth. Chemistry and depth may undergo remarkable variations in water bodies located in arid or semi-arid environments, because of combination of water drainage, seepage into the underlying substrate, and evaporation [20-22]. While all such processes considerably decrease water depth, evaporation can also affect chemical composition by concentrating the vast majority of solutes. To our knowledge, information concerning the impact of drainage, seepage and evaporation on photochemical reactions is hardly available in the literature. To fill in this knowledge gap, we have applied a photochemical model that predicts steady-state concentrations of photoinduced transients ( $\mathrm{OH}, \mathrm{CO}_{3}{ }^{-\bullet},{ }^{1} \mathrm{O}_{2}$ and ${ }^{3} \mathrm{CDOM}^{*}$ ) as a function of variable water chemistry and depth $[23,24]$. The model can also predict pollutant transformation kinetics. Compounds to be modelled were chosen depending on available reactivity data, namely photolysis quantum yield and secondorder reaction rate constants with photoinduced transients. The chosen compounds in this study 
belong to the classes of pharmaceuticals (carbamazepine, CBZ, and ibuprofen, IBU) and pesticide metabolites (2,4-dichloro-6-nitrophenol, DCNP, produced by transformation of phenoxy acid herbicides [25]). Furthermore, the strongly phytotoxic 2,4-dinitrophenol (24DNP) [26] was chosen because it undergoes phototransformation in surface waters almost exclusively by direct photolysis [27]. Therefore, 24DNP is an excellent probe for direct photochemical reactions under the modelled conditions. In the case of the two nitrophenols, the anionic forms were considered because they would prevail over neutral ones in surface waters $\left(p K_{a}{ }^{\mathrm{DCNP}}=4.75, p K_{a}{ }^{24 \mathrm{NP}}=4.08\right)$ [26].

\section{Methods}

Photochemical production of reactive species

Chromophoric dissolved organic matter (CDOM), nitrate and nitrite are the main photosensitisers in most surface waters. Their irradiation produces ${ }^{\circ} \mathrm{OH},{ }^{1} \mathrm{O}_{2}$ and ${ }^{3} \mathrm{CDOM}^{*}$ (CDOM triplet states). Furthermore, oxidation of carbonate and bicarbonate by ${ }^{\circ} \mathrm{OH}$ and carbonate oxidation by ${ }^{3} \mathrm{CDOM}^{*}$ yields $\mathrm{CO}_{3}{ }^{-\bullet}$. The radical ${ }^{\bullet} \mathrm{OH}$ is mostly produced by irradiation of CDOM, nitrate and nitrite, and it is scavenged by DOM, carbonate and bicarbonate [15-17,28]. In salt- or brackish waters, bromide is an important ${ }^{\circ} \mathrm{OH}$ scavenger, too [29].

$$
\begin{aligned}
& \mathrm{CDOM}+\mathrm{hv}+\mathrm{H}_{2} \mathrm{O} \rightarrow{ }^{\bullet} \mathrm{OH}+\mathrm{CDOM}^{-\bullet}+\mathrm{H}^{+} \\
& \mathrm{NO}_{3}{ }^{-}+\mathrm{h} v+\mathrm{H}^{+} \rightarrow{ }^{\bullet} \mathrm{OH}+{ }^{\bullet} \mathrm{NO}_{2} \\
& \mathrm{NO}_{2}^{-}+\mathrm{hv}+\mathrm{H}^{+} \rightarrow{ }^{\bullet} \mathrm{OH}+{ }^{\bullet} \mathrm{NO} \\
& { }^{\bullet} \mathrm{OH}+\mathrm{DOM} \rightarrow \text { Products } \\
& { }^{\bullet} \mathrm{OH}+\mathrm{HCO}_{3}^{-} \rightarrow \mathrm{H}_{2} \mathrm{O}+\mathrm{CO}_{3}^{-\bullet} \\
& { }^{-} \mathrm{OH}+\mathrm{CO}_{3}{ }^{2-} \rightarrow \mathrm{OH}^{-}+\mathrm{CO}_{3}^{-} \\
& { }^{\bullet} \mathrm{OH}+\mathrm{Br}^{-} \rightarrow \mathrm{OH}^{-}+\mathrm{Br}^{\bullet}
\end{aligned}
$$

Note that reaction (1) [30] is not the only process by which CDOM could produce ${ }^{\bullet} \mathrm{OH}$ [31]. The still controversial pathway might also (or in alternative) proceed via a photo-Fenton process [32], which could involve $\mathrm{H}_{2} \mathrm{O}_{2}$ and $\mathrm{Fe}$ complexes having DOM moieties as ligands. As far as reaction (4) is concerned, ${ }^{\circ} \mathrm{OH}$ can react with organic compounds by electron or $\mathrm{H}$-atom abstraction, and by addition to double bonds and aromatic rings [33]. Note that nitrate, nitrite and CDOM compete for sunlight irradiance, and that CDOM acts as an effective inner filter for nitrate and nitrite in deep water [23].

Radiation absorption by CDOM yields excited singlet states that by inter-system crossing (ISC) produce excited triplets $\left({ }^{3} \mathrm{CDOM}^{*}\right)$. The latter can react with dissolved organic compounds by energy, electron or $\mathrm{H}$-atom transfer [17,34]. Additional reactions can take place with $\mathrm{O}_{2}$ to produce ${ }^{1} \mathrm{O}_{2}$ and with carbonate to give $\mathrm{CO}_{3}^{-\bullet}[18,35]$. 


$$
\begin{aligned}
& \mathrm{CDOM}+\mathrm{hv} \rightarrow{ }^{1} \mathrm{CDOM}^{*} \stackrel{I S C}{\longrightarrow}{ }^{3} \mathrm{CDOM}^{*} \\
& { }^{3} \mathrm{CDOM}^{*}+\mathrm{O}_{2} \rightarrow \mathrm{CDOM}+{ }^{1} \mathrm{O}_{2} \\
& { }^{3} \mathrm{CDOM}^{*}+\mathrm{CO}_{3}{ }^{2-} \rightarrow \mathrm{CDOM}^{-\bullet}+\mathrm{CO}_{3} \cdot
\end{aligned}
$$

Reaction (9) and thermal deactivation are the main sinks of ${ }^{3} \mathrm{CDOM}^{*}$ in surface waters and yield an overall first-order deactivation rate constant $k^{{ }_{3} \mathrm{CDOM}^{*}}{ } \sim 5 \cdot 10^{5} \mathrm{~s}^{-1}$ [36]. Singlet oxygen is produced in reaction (9) and mainly inactivated by collision with water molecules, with pseudo-first order inactivation rate constant $k_{1} O_{2}=2.5 \cdot 10^{5} \mathrm{~s}^{-1}$ [37]. The radical $\mathrm{CO}_{3}^{-\bullet}$ is produced by reactions (5), (6) and (10) and mainly scavenged by DOM, with second-order rate constant $k_{C O_{3}^{*}, D O M} \sim 10^{2} \mathrm{~L}(\mathrm{mg}$ C) $)^{-1} \mathrm{~s}^{-1}$ [18]. The reactions of $\mathrm{CO}_{3}^{-\bullet}$ with organic compounds mainly proceed by one-electron abstraction [38]. In addition to the cited transients, additional species such as $\mathrm{O}_{2}^{-\bullet}$ and DOMderived radicals (e.g. peroxy radicals $\mathrm{ROO}^{\circ}$ ) could be involved in photochemical transformation processes in surface waters. However, there is evidence that both $\mathrm{O}_{2}^{-\bullet}$ and $\mathrm{ROO}^{\bullet}$-type radicals would play a minor to negligible role in transformation reactions, compared to ${ }^{3} \mathrm{CDOM}^{*}[39]$.

The reactions introduced so far can be taken into account in a photochemical model that predicts steady-state concentrations of ${ }^{\bullet} \mathrm{OH}, \mathrm{CO}_{3}{ }^{\bullet},{ }^{1} \mathrm{O}_{2}$ and ${ }^{3} \mathrm{CDOM}^{*}$ as a function of water chemistry and depth [23]. The model considers penetration of sunlight at different wavelengths in the water column by means of a Lambert-Beer approach for every single $\lambda$ value (included in the $300-800 \mathrm{~nm}$ range). This is followed by numerical integration over $\lambda$ to obtain the photon fluxes absorbed by photoactive species (CDOM, nitrate and nitrite) and the formation rates of the relevant transients. Competition for irradiance between CDOM, nitrate, nitrite and dissolved pollutants is taken into account in a Lambert-Beer approach. Water absorption spectrum $\mathrm{A}_{1}(\lambda)\left(\mathrm{cm}^{-1}\right.$ units) was modelled by the exponential equation $\mathrm{A}_{1}(\lambda)=(0.45 \pm 0.04) \cdot D O C \cdot \mathrm{e}^{-(0.015 \pm 0.002) \cdot \lambda}$ [40], where DOC is the dissolved organic carbon and $S=0.015 \pm 0.002 \mathrm{~nm}^{-1}$ is the spectral slope. Values of $S$ in the 0.013 $0.017 \mathrm{~nm}^{-1}$ range can be found in a variety of water environments in different locations (inland, both highland and lowland, and near-coastal zones including brackish waters [40-42]).

The optical path length of sunlight into the water body depends on depth, solar zenith angle and water refraction, while reflection of sunlight at the air-water interface can be neglected as a first approximation [43]. Combination of zenith angle and refraction produces an optical path length that is a bit longer than water depth. Note, however, that many ephemeral and fluctuating water bodies would be located in arid zones that are quite common around $30^{\circ}$ latitude (the so-called subtropical ridge). Correction for solar zenith angle and refraction under such conditions [43,44], within $4 \mathrm{~h}$ from noon (when photoreactions are most active) during summer months (when water loss processes are most likely) gives an optical path length that is within 1.15 times the water column depth. Neglecting such a variation greatly simplifies model handling and does not add much to the overall uncertainty. Even at temperate latitudes $\left(\right.$ e.g. $\left.45^{\circ}\right)$ within $4 \mathrm{~h}$ from noon in summer, the optical path length would be at most 1.15-1.20 times the water depth. By comparison, model uncertainty $( \pm \sigma)$ on ${ }^{\circ} \mathrm{OH}$ formation rate is $5 \%$ from nitrate, $10 \%$ from nitrite and $15 \%$ from CDOM, to which a further $15 \%$ uncertainty should be added as far as ${ }^{\circ} \mathrm{OH}$ scavenging is concerned. 
Uncertainty on ${ }^{1} \mathrm{O}_{2}$ and ${ }^{3} \mathrm{CDOM}^{*}$ formation rates from $\mathrm{CDOM}$ is in the $25-30 \%$ range, and it increases to $30-35 \%$ as far as the secondary pathway of $\mathrm{CO}_{3}^{-\bullet}$ formation from ${ }^{3} \mathrm{CDOM}^{*}$ is concerned $[28,40,45]$.

The model calculates steady-state concentrations of ${ }^{\bullet} \mathrm{OH}, \mathrm{CO}_{3}{ }^{\bullet},{ }^{1} \mathrm{O}_{2}$ and ${ }^{3} \mathrm{CDOM}^{*}$ for a sunlight irradiance of $400 \mathrm{~W} \mathrm{~m}^{-2}\left(290-800 \mathrm{~nm}\right.$, of which $22 \mathrm{~W} \mathrm{~m}^{-2}$ in the UV region, 290-400 nm) [23]. It would correspond for instance to 9.50 am on cloudless 15 July at $30^{\circ}$ latitude, and to 10 am on cloudless 15 July at $45^{\circ}$ latitude $[28,44]$. It is possible to model the transformation kinetics of pollutants from concentration values of transients, provided that the relevant second-order reaction rate constants are known [45]. Indeed, pseudo-first order degradation rate constants are obtained as the product between second-order rate constants and steady-state concentrations of transients, and one has to know the average transient concentrations in the whole water column. For this reason, the model returns column-averaged $\left[{ }^{\bullet} \mathrm{OH}\right],\left[\mathrm{CO}_{3}^{-\bullet}\right],\left[{ }^{1} \mathrm{O}_{2}\right]$ and $\left[{ }^{3} \mathrm{CDOM}^{*}\right]$ rather than their trend with depth. The model also predicts transformation kinetics by direct photolysis, based on pollutant (and water) absorption spectrum and on photolysis quantum yields [46].

An important issue is that the model takes well-mixed surface water into account. In the case of sufficiently shallow lakes, mixing can be relevant to the whole column. In the case of deep and stratified lakes, it is relevant to the epilimnion. The present work does not consider depth values higher than $10 \mathrm{~m}$, thus thorough mixing can be reasonably assumed. Mixing has an important consequence on pollutant phototransformation because it maintains constant concentration values of pollutants within the column. In contrast, the steady-state concentrations of photoinduced transients are considerably higher at the water surface than in the deeper layers, because of higher sunlight irradiance at the surface. Phototransformation would mostly take place at the surface but the development of a pollutant concentration gradient with depth is prevented by mixing, which is usually faster than photochemical reactions. As a consequence, the transformation kinetics of a pollutant by e.g. ${ }^{\circ} \mathrm{OH}$ in a well-mixed water column depends on the mean $\left[{ }^{\circ} \mathrm{OH}\right]$ within the whole column, which averages the elevated surface concentrations and the much lower ones at the bottom [47]. The same issue holds for other photoinduced transients. In our model, the reported steady-state concentrations of transients are averages within a water column of depth $d$.

The time unit adopted by our model is the time taken by sunlight in cloudless sky to deliver $7.5 \cdot 10^{5} \mathrm{~J} \mathrm{~m}^{-2} \mathrm{UV}$ energy to the ground (e.g., 9.5 hours of light at an average UV irradiance of $22 \mathrm{~W}$ $\mathrm{m}^{-2}$ ) [23,24]. Hereafter, this will be the meaning of the term "day" as far as the model output is concerned (note that modelled pseudo-first order degradation rate constants have units of day ${ }^{-1}$ ). Such a time unit corresponds for instance to fair-weather $15 \mathrm{July}$ at $45^{\circ}$ latitude or to 25 August at $30^{\circ}$ latitude $[28,44]$. A more complete description of the model, including all the model equations is reported as Supplementary Online Material (SOM). 


\section{Model application to fluctuating water environments}

Water bodies in arid and semi-arid regions are often characterised by very large fluctuations of the water level, sometimes up to complete desiccation in the dry season because water loss is not compensated for by inflow or precipitation [12-14]. Water loss may occur by several phenomena including surface drainage, seepage or evaporation, the most likely scenario being a combination of the three processes. Both drainage and seepage would modify water depth (taken here as the average depth of the water body), with limited effect on water chemistry. Therefore, they will be considered together under the term "outflow" and no further differentiated. Three scenarios were taken into account in this work: the two extreme conditions of pure outflow and pure evaporation, basically to get insight into the effect of such processes on photochemistry, and a mixed case where half of the water is lost by outflow and the other half by evaporation. In the pure outflow scenario, concentration values of solutes would be constant as a first approximation when the water level decreases. We assume an initial condition with depth $d_{\mathrm{o}}=10 \mathrm{~m}$ and solute concentration $c_{\mathrm{o}}$. We also assume $d<d_{\mathrm{o}}$ as the column depth value resulting from water loss, with $f=d d_{\mathrm{o}}^{-1}$ as the fraction of initial depth. In the absence of other phenomena, the concentration of a given solute for $f$ $<1$ would be $c=c_{\mathrm{o}}$. In the evaporation scenario, as a first approximation the mass of solutes is preserved and concentration values increase as the volume decreases. Abiotic or biochemical processes can be operational and further modify the concentration of inorganic ions or of DOC. However, such events are expected to be quite different in different water bodies and they were not considered here, but a caveat concerning $\mathrm{CaCO}_{3}$ precipitation is commented where relevant. Because of evaporation, the concentration $c$ of a given solute at a fraction $f<1$ of the initial depth is $c=c_{\mathrm{o}} f^{-1}$, where $c_{\mathrm{o}}$ is the concentration at $d_{\mathrm{o}}=10 \mathrm{~m}$. In the mixed scenario, half of the water is lost by outflow and half by evaporation. In such a case, the following equation holds for solute concentration at the usual fraction $f<1$ of the initial depth:

$$
c=\frac{c_{o}}{2}\left(\frac{f+1}{f}\right)
$$

In the above discussion it is hypothesised that water is thoroughly mixed. This is obviously an approximation, which is nevertheless justified in shallow waters. In all three scenarios the photochemical model was used to determine variations of the column-averaged steady-state concentrations of photoinduced transients $\left({ }^{\bullet} \mathrm{OH}, \mathrm{CO}_{3}{ }^{\bullet},{ }^{1} \mathrm{O}_{2}\right.$ and $\left.{ }^{3} \mathrm{CDOM}^{*}\right)$, and of the photodegradation kinetics of model pollutants. As far as the latter are concerned, compounds were chosen for which reaction rate constants with the relevant transients are available. Selected compounds were: $(i)$ the anti-epileptic drug carbamazepine (CBZ), which undergoes degradation mostly by direct photolysis and ${ }^{\circ} \mathrm{OH}$ reaction [48]; (ii) anti-inflammatory ibuprofen (IBU), transformed by direct photolysis, ${ }^{\circ} \mathrm{OH}$ and ${ }^{3} \mathrm{CDOM}^{*}$ [49]; (iii) 2,4-dichloro-6-nitrophenol (DCNP), a toxic secondary pollutant [50] that derives from phenoxyacetic acid herbicides [25] (DCNP is 
mainly degraded by direct photolysis, ${ }^{\bullet} \mathrm{OH}$ and ${ }^{1} \mathrm{O}_{2}$ [51]); and (iv) 2,4-dinitrophenol (24DNP), used in several industrial applications or formed as secondary pollutant [52]. 24DNP is mostly transformed by direct photolysis [27]. Photolysis depends on competition for irradiance between substrate and other water components [40], but it is independent of the steady-state concentrations of photoinduced transients. This issue accounts for the choice of 24DNP in this work. Table 1 reports available data for reaction rate constants and quantum yields of the studied compounds. The photolysis quantum yield of IBU is particularly high, but it is largely offset by the very limited ability of this compound to absorb sunlight [49]. In contrast, the much lower quantum yield of 24DNP is largely compensated for by the substrate ability to absorb sunlight between 300 and 500 $\mathrm{nm}$ [53]. In the case of CBZ, IBU and DCNP, the model has been validated for its ability to predict substrate transformation kinetics under field conditions $[48,49,51]$.

In the case of outflow, where concentration values of solutes would not vary, it was possible to extend the model to near-zero depth. In the other scenarios, water evaporation might increase solute concentration values beyond the levels where the model has the support of experimental data $[28,40,45]$. Under such circumstances, scavenging by DOM of ${ }^{3} \mathrm{CDOM}^{*}$ and ${ }^{1} \mathrm{O}_{2}$ could for instance become significant [54]. Moreover, phenolic antioxidants present in DOM could substantially inhibit ${ }^{3} \mathrm{CDOM}^{*}$-sensitised transformation of organic pollutants [55]. To prevent the model from producing questionable data, in the evaporative and mixed scenarios the simulation was only performed down to $f=0.1$, which corresponds to $1 \mathrm{~m}$ depth and (in the evaporative scenario) 10 fold solute concentration compared to $f=1$. Lower $f$ values (shallower water, implying higher solute concentrations if evaporation takes place) were not taken into account.

As far as water chemical composition is concerned, two cases were considered: in case A, nitrate $(0.1 \mathrm{mM})$ and nitrite $(1 \mu \mathrm{M})$ would be important ${ }^{\circ} \mathrm{OH}$ sources, in case B they would play a minor role (concentration values of $1 \mu \mathrm{M}$ and $10 \mathrm{nM}$, respectively). Other chemical parameters were in both cases as follows: $1 \mathrm{mg} \mathrm{C} \mathrm{L}^{-1} \mathrm{DOC}, 0.5 \mathrm{mM}$ bicarbonate, $10 \mu \mathrm{M}$ carbonate. The model results would best apply to lakes with a fluctuating water level, but some conclusions can be extended to rivers as well. To highlight water loss in the different scenarios, model results are plotted as a function of the fraction $f$ of the initial depth, taken as $d_{\mathrm{o}}=10 \mathrm{~m}$. The lower is $f$, the higher is the water loss and the shallower is the water column.

\section{Results and Discussion}

\section{Effects on photoinduced transients}

Figure 1 reports the trends with $f$ of column-averaged $\left[{ }^{\bullet} \mathrm{OH}\right],\left[\mathrm{CO}_{3}{ }^{\bullet}\right],\left[{ }^{1} \mathrm{O}_{2}\right]$ and $\left[{ }^{3} \mathrm{CDOM} *\right]$ in case A ( $0.1 \mathrm{mM}$ nitrate, $1 \mu \mathrm{M}$ nitrite), in the three different scenarios of outflow (1a), evaporation (1b) and the mixed process (1c). It is $d_{\mathrm{o}}=10 \mathrm{~m}$ and data are plotted as a function of decreasing $f$, thus in the direction of increasing water loss. Note that $\mathrm{CO}_{3}^{-\bullet}$ was the transient occurring at the highest 
concentration, while ${ }^{\bullet} \mathrm{OH}$ often had the lowest concentration values. The main reason for $\left[{ }^{\circ} \mathrm{OH}\right]<$ $\left[\mathrm{CO}_{3}^{-\bullet}\right]$ is that ${ }^{\bullet} \mathrm{OH}$ is much more reactive than $\mathrm{CO}_{3}{ }^{-\bullet}$ towards DOM. This reactivity difference is usually maintained in the case of dissolved pollutants [56,57], and it can compensate for the lower steady-state concentration of ${ }^{\bullet} \mathrm{OH}$. To allow all concentration values to be plotted against the same $\mathrm{Y}$-axis and to maintain plot readability, $\left[\mathrm{CO}_{3}^{-\bullet}\right.$ ] was divided by a factor of 10 or even 100 and $\left[^{\circ} \mathrm{OH}\right]$ was often multiplied by 10 . In such cases, indications are reported on the plots.

Figure 1a shows that all concentrations increase with decreasing $f$. Remembering that the reported concentration values are averages over the whole column, their increase is a consequence of the fact that the bottom layers of a deep water body are poorly illuminated by sunlight. Transient concentrations in the deeper zone are very low, and cause a decrease of column-averaged values when $f$ is high. In contrast, a shallow water body is more efficiently illuminated and, with fewer dark zones, the average steady-state concentrations of photoinduced transients are higher at low $f$.

$\left[{ }^{3} \mathrm{CDOM}^{*}\right]$ and $\left[{ }^{1} \mathrm{O}_{2}\right]$ show a parallel increase with decreasing $f$, because they are both produced by the same species $(\mathrm{CDOM}) .\left[{ }^{\bullet} \mathrm{OH}\right]$ and $\left[\mathrm{CO}_{3}{ }^{-\bullet}\right]$ increase more steeply than $\left[{ }^{3} \mathrm{CDOM}^{*}\right]$ and $\left[{ }^{1} \mathrm{O}_{2}\right]$ with decreasing $f$, thus a further effect should be operational in addition to better illumination of shallow vs. deep water. Considering that concentration values of nitrate, nitrite, DOC, carbonate and bicarbonate do not vary in the outflow scenario, the main issue here would be competition for irradiance between nitrate, nitrite and $\mathrm{CDOM}$. Note that ${ }^{\circ} \mathrm{OH}$ would be produced by nitrate, nitrite and $\mathrm{CDOM}, \mathrm{CO}_{3}{ }^{-}$mostly by reaction between ${ }^{\circ} \mathrm{OH}$ and carbonate/bicarbonate, while ${ }^{1} \mathrm{O}_{2}$ and ${ }^{3} \mathrm{CDOM}^{*}$ would be produced by $\mathrm{CDOM}$ alone. CDOM itself is the main radiation absorber in surface waters between 300 and $500 \mathrm{~nm}$ [58]. It acts as a filter that decreases the radiation absorption by nitrate and nitrite to an extent that depends on wavelength and depth. The screening effect of CDOM is higher in the UVB than in the UVA region, thus it affects UVB-absorbing nitrate more than nitrite, which has an absorption maximum in the UVA [59,60]. If $f$ is very low (very shallow water), the three species absorb radiation almost independently and radiation absorption by nitrate and nitrite is not decreased by CDOM. With increasing $f$, the filter effect by CDOM becomes more important and decreases the absorption of radiation by nitrate and nitrite. Therefore, at high $f$ most ${ }^{\circ} \mathrm{OH}$ would be produced by CDOM. At low $f$ nitrate and nitrite would contribute more to ${ }^{\circ} \mathrm{OH}$ generation, adding to the $\mathrm{CDOM}$ contribution and causing higher [ ${ }^{\circ} \mathrm{OH}$ ] to be reached. That would in turn produce higher $\left[\mathrm{CO}_{3}^{-\bullet}\right]$, because of enhanced oxidation of carbonate and bicarbonate (reactions 5, 6).

Figure $1 \mathrm{~b}$ reports steady-state concentrations as a function of $f$ in the evaporation scenario (evaporative solute concentration). Note that $\left[{ }^{3} \mathrm{CDOM}^{*}\right]$ and $\left[{ }^{1} \mathrm{O}_{2}\right]$ increase with decreasing $f$, while $\left[{ }^{\bullet} \mathrm{OH}\right]$ and $\left[\mathrm{CO}_{3}^{-\bullet}\right]$ are constant. Assuming as done here that solute mass is conserved during evaporation, concentration values would be $c=c_{\mathrm{o}} f^{-1}$. According to the Lambert-Beer law, the absorbance of a given solute at the wavelength $\lambda$ is $A_{\lambda}=100 \varepsilon_{\lambda} d c=100 \varepsilon_{\lambda} f d_{o} c$, where $\varepsilon_{\lambda}$ (units of $\mathrm{M}^{-1} \mathrm{~cm}^{-1}$ ) is a molar absorption coefficient and $d=f d_{o}$. The factor of 100 is introduced because depth is expressed in metres and not in centimetres. It is $c f=c_{0}$, thus the absorbance of solutes (including CDOM, nitrate and nitrite) would be $A_{\lambda}=100 \varepsilon_{\lambda} d_{o} c_{0}$, independent of $f$. Because $f$ 
variation does not modify absorbance values, it would not affect competition for irradiance between CDOM, nitrate and nitrite (differently from the case of outflow). The reported trends of steady-state concentrations of transients can be explained by phenomena that follow radiation absorption. Constant absorbance of water with $f$ means that the number of absorbed photons $N_{P}$ is always the same in the whole volume while evaporation proceeds. The number of absorbed photons per unit volume $V\left(n_{P}=N_{P} V^{-1}\right)$ is inversely proportional to $f$, because $V \propto f$. In other words, $n_{P}$ increases with decreasing $f$ because sunlight-absorbing solutes are concentrated by water evaporation. For the same reason, the absorbed photon fluxes per unit volume $\left(P_{a}^{\mathrm{NO}_{3}^{-}}, P_{a}^{\mathrm{NO}_{2}^{-}}, P_{a}^{C D O M}\right)$ are $\propto f^{-1}$. The relevant formation rates of photoinduced transients $\left(R_{\bullet_{\mathrm{OH}}},{R_{1} \mathrm{O}_{2}}\right.$ and $\left.R_{{ }^{3} \mathrm{CDOM}}\right)$ are the product of absorbed photon fluxes times depth-independent quantum yields [23,24], and they are $\propto f^{-1}$ as well. Steady-state concentrations of transients are obtained as the ratio between formation rates and scavenging (or deactivation) rate constants. For instance, $\left[{ }^{1} \mathrm{O}_{2}\right]=R_{1} \mathrm{O}_{2} \cdot{ }^{1} \mathrm{O}_{2}^{-1}$. In this case, the deactivation rate constant $k_{1} O_{2}$ depends on ${ }^{1} \mathrm{O}_{2}$ collisions with solvent molecules and is independent of the concentration of solutes (at least if DOC is not too high, for which reason the modelling was not extended to $f<0.1$ ) [37]. Because $R_{{ }_{1}} \propto f_{2}^{-1}$ and $k_{{ }_{1} O_{2}}$ is independent of $f$, it is also [ $\left.{ }^{1} \mathrm{O}_{2}\right] \propto f^{-1}$ (coherently with data of Figure 1b). A similar issue holds for $\left[{ }^{3} \mathrm{CDOM}^{*}\right]$, because $R_{3}{ }_{\mathrm{CDOM}}^{*} \propto f^{-1}$ but ${ }^{3} \mathrm{CDOM}^{*}$ deactivation would not be significantly modified with decreasing $f$, at least at the investigated $f$ values.

The case of ${ }^{\bullet} \mathrm{OH}$ is different, because it is scavenged by compounds (DOM, carbonate and bicarbonate [28]) that would undergo evaporative concentration. Assuming $k_{\bullet_{\mathrm{OH}, \mathrm{DOC}}}, k_{\bullet_{\mathrm{OH}_{\mathrm{HCO}}^{-}}}$and $k_{{ }_{\mathrm{OH}, \mathrm{CO}_{3}^{2-}}}$ as the second-order reaction rate constants of ${ }^{\circ} \mathrm{OH}$ with $\mathrm{DOC}, \mathrm{HCO}_{3}{ }^{-}$and $\mathrm{CO}_{3}{ }^{2-}$, respectively, and $k_{\bullet_{\mathrm{OH}}}$ as the pseudo-first order scavenging rate constant of ${ }^{\bullet} \mathrm{OH}$, one has:

$$
k_{\bullet_{\mathrm{OH}}}=k_{\bullet_{\mathrm{OH}, \mathrm{DOC}}} \mathrm{DOC}+k_{\mathrm{OH}_{\mathrm{H}, \mathrm{HCO}}^{-}}\left[\mathrm{HCO}_{3}^{-}\right]+k_{\mathrm{OH}_{,} \mathrm{CO}_{3}^{2-}}\left[\mathrm{CO}_{3}^{2-}\right]
$$

Because of evaporative concentration, DOC, $\left[\mathrm{HCO}_{3}{ }^{-}\right]$and $\left[\mathrm{CO}_{3}{ }^{2-}\right] \propto f^{-1}$ and one gets $k_{{ }_{\mathrm{OH}}} \propto f^{-1}$ as well. The ${ }^{\bullet} \mathrm{OH}$ formation rate $\left(R_{\bullet_{\mathrm{OH}}}\right)$ is inversely proportional to $f\left(R_{\bullet_{\mathrm{OH}}} \propto f^{-1}\right)$ as explained above. Therefore, $\left[{ }^{\bullet} \mathrm{OH}\right]=R \cdot_{{ }_{O H}} \cdot k_{\bullet_{O H}}^{-1}$ would be independent of $f$.

A similar issue (independence of $f$ ) holds for $\mathrm{CO}_{3}^{-\bullet}$, because it is mainly produced by ${ }^{\bullet} \mathrm{OH}$ and scavenged by DOM. Note, however, that evaporative concentration might cause precipitation of $\mathrm{CaCO}_{3}$ in Ca-rich water [61]. This phenomenon would deplete inorganic carbon forms and would decrease both $\mathrm{CO}_{3}^{-\bullet}$ formation rate and steady-state $\left[\mathrm{CO}_{3}^{-\bullet}\right]$. The same issue would be less important in $\mathrm{Mg}$-rich and Ca-poor water, because $\mathrm{MgCO}_{3}$ is more soluble than $\mathrm{CaCO}_{3}$ [62].

Figure $1 \mathrm{c}$ reports the trends with $f$ of $\left[{ }^{\bullet} \mathrm{OH}\right],\left[\mathrm{CO}_{3}{ }^{\bullet}\right],\left[{ }^{1} \mathrm{O}_{2}\right]$ and $\left[{ }^{3} \mathrm{CDOM}^{*}\right]$ in the mixed scenario, where half of water is lost by evaporation and half by outflow. Intermediate conditions between previous cases account for the similar trends of ${ }^{\bullet} \mathrm{OH}$ and $\mathrm{CO}_{3}{ }^{-}$and of ${ }^{1} \mathrm{O}_{2}$ and ${ }^{3} \mathrm{CDOM}^{*}$. 
Interestingly, $\left[{ }^{1} \mathrm{O}_{2}\right]$ and $\left[{ }^{3} \mathrm{CDOM}^{*}\right]$ undergo a more marked increase with decreasing $f$ compared to $\left[{ }^{\bullet} \mathrm{OH}\right]$ and $\left[\mathrm{CO}_{3}^{-\bullet}\right]$.

Figure 2 compares the impact of the three different scenarios of outflow, evaporation and the mixed one, in case $\mathrm{A}(0.1 \mathrm{mM}$ nitrate and $1 \mu \mathrm{M}$ nitrite $)$ on the column-averaged steady-state concentrations of ${ }^{\bullet} \mathrm{OH}(2 \mathrm{a}), \mathrm{CO}_{3}{ }^{\bullet}(2 \mathrm{~b}),{ }^{1} \mathrm{O}_{2}$ (2c) and ${ }^{3} \mathrm{CDOM}^{*}$ (2d). To allow easier comparison, data are plotted in the range $1 \geq f \geq 0.1$ for all the scenarios. It clearly appears from the figure that $\left[{ }^{\bullet} \mathrm{OH}\right]$ and $\left[\mathrm{CO}_{3}^{-\bullet}\right]$ are highly enhanced by outflow, while the largest increase of $\left[{ }^{1} \mathrm{O}_{2}\right]$ and $\left[{ }^{3} \mathrm{CDOM}^{*}\right]$ is observed in the case of evaporation. A first conclusion that can be drawn is that outflow would favour processes induced by ${ }^{\bullet} \mathrm{OH}$ and $\mathrm{CO}_{3}{ }^{-\bullet}$, while evaporation would enhance reactions involving ${ }^{1} \mathrm{O}_{2}$ and ${ }^{3} \mathrm{CDOM}^{*}$. In the mixed case, the increase of $\left[{ }^{1} \mathrm{O}_{2}\right]$ and $\left[{ }^{3} \mathrm{CDOM}^{*}\right]$ with decreasing $f$ would be more important compared to $\left[{ }^{\bullet} \mathrm{OH}\right]$ and $\left[\mathrm{CO}_{3}{ }^{\bullet}\right]$.

Figure 3 reports the trends of $\left[{ }^{\bullet} \mathrm{OH}\right],\left[\mathrm{CO}_{3}{ }^{-\bullet}\right],\left[{ }^{1} \mathrm{O}_{2}\right]$ and $\left[{ }^{3} \mathrm{CDOM}^{*}\right]$ as a function of $f$, in case $\mathrm{B}$ (low nitrate and nitrite: $1 \mu \mathrm{M}$ and $10 \mathrm{nM}$, respectively) for the scenarios of outflow (3a), evaporation ( $3 b$ ) and mixed ( $3 c)$. Differently from previous case A, here nitrate and nitrite would play a minor role as ${ }^{\bullet} \mathrm{OH}$ sources. $\mathrm{CDOM}$ would account for the majority of ${ }^{\bullet} \mathrm{OH}$ photoproduction, in addition to generating ${ }^{1} \mathrm{O}_{2}$ and ${ }^{3} \mathrm{CDOM}^{*}$. Figure $3 \mathrm{a}$ shows that all transients undergo quite similar increase with decreasing $f$, differently from Figure 1 a (case $\mathrm{A}$ ) where $\left[{ }^{\bullet} \mathrm{OH}\right]$ and $\left[\mathrm{CO}_{3}^{-\bullet}\right]$ increased much more than $\left[{ }^{1} \mathrm{O}_{2}\right]$ and $\left[{ }^{3} \mathrm{CDOM} *\right]$. Such a difference can be accounted for by the prevalence of CDOM photochemistry in case B. Here competition for irradiance between nitrate, nitrite and CDOM is still operational and decreases at low $f$, but enhanced nitrate and nitrite photochemistry has limited impact on ${ }^{\bullet} \mathrm{OH}$ photoproduction that is dominated by CDOM. The $\mathrm{CO}_{3}{ }^{-\bullet}$ trend largely follows the ${ }^{\circ} \mathrm{OH}$ one, because $\mathrm{CO}_{3}{ }^{-\bullet}$ mainly arises upon $\mathrm{HCO}_{3}{ }^{-}$and $\mathrm{CO}_{3}{ }^{2-}$ oxidation by ${ }^{\bullet} \mathrm{OH}$.

Figure $3 \mathrm{~b}$ reports the trend of steady-state concentrations in the evaporation scenario. $\left[{ }^{3} \mathrm{CDOM}^{*}\right]$ and $\left[{ }^{1} \mathrm{O}_{2}\right]$ increase with decreasing $f$ for the same reasons already discussed in case $\mathrm{A}$, while $\left[{ }^{\circ} \mathrm{OH}\right]$ keeps constant. In case B the steady-state $\left[{ }^{\circ} \mathrm{OH}\right]$ is considerably lower than in case A (compare Figures $1 \mathrm{~b}$ and $3 \mathrm{~b}$ ), thus carbonate oxidation by ${ }^{3} \mathrm{CDOM}^{*}$ would play a more important role as $\mathrm{CO}_{3}^{-\bullet}$ source. This issue accounts for the limited but non-negligible increase of $\left[\mathrm{CO}_{3}^{-\bullet}\right]$ with decreasing $f$. The caveat formulated above for $\mathrm{CaCO}_{3}$ precipitation would also apply in this case, and precipitation of $\mathrm{CaCO}_{3}$ could offset the predicted increase of $\left[\mathrm{CO}_{3}^{-\bullet}\right]$.

Figure $3 \mathrm{c}$ reports the trends in the mixed scenario. $\left[{ }^{3} \mathrm{CDOM}^{*}\right]$ and $\left[{ }^{1} \mathrm{O}_{2}\right]$ undergo higher increase with decreasing $f$ than $\left[{ }^{\circ} \mathrm{OH}\right]$ and $\left[\mathrm{CO}_{3}^{-\bullet}\right]$, in analogy with case A already reported.

When considering the overall results shown in Figures 1-3, one sees that a decreasing water depth would be generally favourable to photochemical processes. This may happen either because the water body is better illuminated, or because the same processes take place in a smaller volume. These issues would influence the various photochemical reactions to a different extent. Outflow is expected to enhance all processes, but those involving ${ }^{\bullet} \mathrm{OH}$ and $\mathrm{CO}_{3}{ }^{-}$more than ${ }^{3} \mathrm{CDOM}^{*}$ and ${ }^{1} \mathrm{O}_{2}$, particularly if nitrate and nitrite are significant ${ }^{\circ} \mathrm{OH}$ sources. Conversely, evaporative concentration would enhance ${ }^{3} \mathrm{CDOM}^{*}$ and ${ }^{1} \mathrm{O}_{2}$. 


\section{Effects on pollutant phototransformation}

Figure 4 reports the overall first-order transformation rate constants of CBZ, IBU, DCNP and 24DNP, as a function of $f$. As usual, relevant scenarios are outflow (4a), evaporation (4b) and the mixed one (4c). Data were computed for case A, namely high nitrate and nitrite $(0.1 \mathrm{mM}$ and $1 \mu \mathrm{M}$, respectively). There is a general increase of the rate constant values with decreasing $f$, because photochemistry would proceed faster as water becomes shallower. However, details are different depending on substrate and scenario. In the case of outflow (4a), reaction rate constants of CBZ and IBU undergo higher increase with decreasing $f$ compared to DCNP and 24DNP. While no selected compound reacts significantly with $\mathrm{CO}_{3}{ }^{\bullet}$ (see Table 1), the role of ${ }^{\bullet} \mathrm{OH}$ in phototransformation decreases in the order CBZ (over 80\%) > IBU (25-30\% depending on $f$ ) > DCNP (15-30\%) > 24DNP (5-10\%). Therefore, CBZ and IBU are more affected than other substrates by the very significant increase of ${ }^{\circ} \mathrm{OH}$ as water becomes shallower (see Figure 1a). Note that 24DNP would mainly be transformed by direct photolysis, and the increase of its transformation rate constant has similar explanation as for CDOM photolysis: the reaction is faster in shallow water because the bottom layers of a deeper water body are poorly illuminated by sunlight.

Figure $4 \mathrm{~b}$ reports rate constant values $v s . f$ in the evaporation scenario, showing that the rate constants of IBU and DCNP undergo a more important increase with decreasing $f$ compared to CBZ and 24DNP. In the case of CBZ $60-85 \%$ of transformation would be accounted for by ${ }^{\circ} \mathrm{OH}$, the steady-state concentration of which would not vary during evaporative concentration (see Figure 1b). The relative importance of the ${ }^{\bullet} \mathrm{OH}$ reaction is lower at low $f$, which accounts for the fact that CBZ rate constant increases under such circumstances (mostly due to ${ }^{3} \mathrm{CDOM}^{*}$ having increased concentration). 24DNP would be transformed by ${ }^{\circ} \mathrm{OH}(\sim 5 \%)$ and most notably by direct photolysis $(\sim 95 \%)$. The photolysis rate constant of 24DNP is predicted not to change with changing $f$. To understand this, one should consider the competition for sunlight irradiance, as a function of $f$, between 24DNP and the other water components. At any relevant wavelength $\lambda$, the dependence of the photon flux density absorbed by 24DNP $\left(p_{a}^{24 D N P}(\lambda)\right)$ on the absorbance values of 24DNP and water is described by equation (13) [63]. Note that $A_{\mathrm{w}}(\lambda)=100 A_{1}(\lambda) d=100 A_{1}(\lambda) f d_{\mathrm{o}}$ and $A_{24 \mathrm{DNP}}(\lambda)=100 \varepsilon_{24 \mathrm{DNP}}(\lambda)$ [24DNP] $f d_{0}$, see SOM, where 100 is the conversion factor between $\mathrm{cm}$ and $\mathrm{m}, A_{1}(\lambda)$ is the water absorption spectrum in $\mathrm{cm}^{-1}$, [24DNP] has M units, $\varepsilon_{24 \mathrm{DNP}}(\lambda)$ is in $\mathrm{M}^{-1}$ $\mathrm{cm}^{-1}, d_{\mathrm{o}}=10 \mathrm{~m}, p^{\circ}(\lambda)$ is the incident photon flux density of sunlight, $p_{a}^{w}(\lambda)$ is the photon flux density absorbed by water, and $\mathrm{A}_{24 \mathrm{DNP}}(\lambda) \ll \mathrm{A}_{\mathrm{w}}(\lambda)$.

$$
p_{a}^{24 D N P}(\lambda)=\frac{A_{24 D N P}(\lambda)}{A_{w}(\lambda)} p_{a}^{w}(\lambda)=\frac{\varepsilon_{24 D N P}(\lambda)[24 D N P]}{A_{1}(\lambda)} p^{\circ}(\lambda)\left(1-10^{-100 A_{1}(\lambda) f d_{o}}\right)
$$

Evaporative concentration would increase both [24DNP] and DOC, thus it would be [24DNP] $\propto f^{-1}$ and $\mathrm{A}_{1}(\lambda) \propto f^{-1}$, the latter because $\mathrm{A}_{1}(\lambda) \propto$ DOC (see SOM, equation 1). If [24DNP] $]_{o}$ and $A_{1}^{o}(\lambda)$ 
are the values referred to $d_{\mathrm{o}}=10 \mathrm{~m}$, one obtains $[24 \mathrm{DNP}]=[24 \mathrm{DNP}]_{\mathrm{o}} f^{-1}$ and $\mathrm{A}_{1}(\lambda)=A_{1}^{o}(\lambda) f^{-1}$. On this basis, equation (13) is transformed as follows:

$$
p_{a}^{24 D N P}(\lambda)=\frac{\varepsilon_{24 D N P}(\lambda)[24 D N P]_{o}}{A_{1}^{o}(\lambda)} p^{\circ}(\lambda)\left(1-10^{-100 A_{1}^{o}(\lambda) d_{o}}\right)
$$

Note that $p_{a}^{24 D N P}(\lambda)$ and $p^{\circ}(\lambda)$ are independent of $f$ (equation 14) and have units of Einstein $\mathrm{cm}^{-2}$ $\mathrm{s}^{-1} \mathrm{~nm}^{-1}$ (see Figure SOM1). The photon flux absorbed by 24DNP in the water volume (units of Einstein $\mathrm{L}^{-1} \mathrm{~s}^{-1}$ ) can be expressed as follows (see also equation 24 in SOM) [63]:

$$
P_{a}^{24 D N P}=10 d^{-1} \int_{\lambda} p_{a}^{24 D N P}(\lambda) d \lambda=10\left(f d_{o}\right)^{-1} \int_{\lambda} p_{a}^{24 D N P}(\lambda) d \lambda
$$

Therefore, it is $P_{a}^{24 D N P} \propto f^{-1}$. The product $\Phi_{24 D N P} P_{a}^{24 D N P}$ (where $\Phi_{24 D N P}=3.4 \cdot 10^{-5}$ is the photolysis quantum yield of 24DNP [50]) gives the rate $R_{24 D N P} \propto f^{-1}$ of $24 \mathrm{DNP}$ transformation. The corresponding first-order rate constant is $k_{24 D N P}^{\text {phot }}=R_{24 D N P}[24 D N P]^{-1}$, where both $R_{24 D N P}$ and [24DNP] are proportional to $f^{-1}$ and, therefore, $k_{24 D N P}^{\text {phot }}$ is independent of $f$. Because direct photolysis is the major transformation pathway for 24DNP $\left(k_{24 D N P}^{\text {phot }} \approx k_{24 D N P}^{\text {tot }}\right)$, this issue accounts for the constant value of $k_{24 D N P}^{\text {tot }} v s . f$ in Figure $4 \mathrm{~b}$. Finally, the important increase of the degradation rate constants of DCNP and IBU with decreasing $f$ is accounted for by increasing $\left[{ }^{1} \mathrm{O}_{2}\right]$ and $\left[{ }^{3} \mathrm{CDOM}^{*}\right]$, respectively.

Figure $4 \mathrm{c}$ shows the rate constants trend in the mixed scenario, for which the model predicts an overall enhancement of phototransformation kinetics with decreasing $f$, to a higher extent for IBU and DCNP compared with CBZ and 24DNP.

Figure 5 reports rate constant trends with $f$ in case $\mathrm{B}$ (low nitrate and nitrite). Figure 5a represents the outflow scenario, where the increase of CBZ and IBU rate constants with decreasing $f$ is less marked than in Figure 4a (referred to case A). In case B the importance of ${ }^{\circ} \mathrm{OH}$ in phototransformation is lower than in case A, and there is a comparatively more important role of other processes (e.g. direct photolysis and $\left.{ }^{3} \mathrm{CDOM}^{*}\right)$. As far as $24 \mathrm{DNP}$ is concerned, the rate constant increase is almost totally accounted for by enhanced direct photolysis: ${ }^{\circ} \mathrm{OH}$ reaction contributes less than $2 \%$ to 24DNP transformation under these circumstances.

Figure $5 \mathrm{~b}$ reports the rate constants in the evaporation scenario. The flat trend of 24DNP is due to direct photolysis (contributing to $>98 \%$ transformation) and has the same explanation as for Figure 4 b. CBZ rate constant does not vary between $0.6<f<1.0$, where ${ }^{\circ} \mathrm{OH}$ accounts for over $50 \%$ transformation and direct photolysis is also important. The increase of the CBZ rate constant at low $f$ is due to enhanced ${ }^{3} \mathrm{CDOM}^{*}$ reaction. Reactions with ${ }^{3} \mathrm{CDOM}^{*}$ and ${ }^{1} \mathrm{O}_{2}$ also account for the rate constant increase of IBU and DCNP with decreasing $f$. Figure $5 \mathrm{c}$ reports the trends in the mixed scenario, where the rate constants of IBU and DCNP undergo a more important increase with decreasing $f$ compared to $24 \mathrm{DNP}$ and CBZ. 
An interesting issue of Figures 4 and 5 is that photochemical reactions are predicted to be quite fast when $f$ is low. The corresponding half-life times of substrates would be a few days, meaning that photochemical processes could be important not only in lakes, where water residence time can be high, but in some cases also in rivers where the time available for light-induced processes is usually lower [64].

\section{Conclusions}

It is possible to model the effects of water loss on photochemical processes, with the exception of extreme phenomena that could be caused by evaporation. The latter may produce too high solute concentrations, compared to experimental data on which the adopted photochemical model is based.

Water loss can be due to outflow (combination of surface drainage and seepage, which would mostly preserve solute concentration values), evaporation (which preserves the mass of solutes while their concentrations increase) or, most frequently, some combination of both. Under the above circumstances, the overall photochemical transformation kinetics of pollutants would be enhanced as water is lost. Different photochemical reactions would be affected to a different extent, also depending on the prevailing mechanism of water loss. Outflow would enhance all processes, but particularly those involving ${ }^{\circ} \mathrm{OH}$ and $\mathrm{CO}_{3}{ }^{-\bullet}$ if nitrate and nitrite play a significant role as ${ }^{\bullet} \mathrm{OH}$ sources. The reason is that in shallow water nitrate and nitrite undergo less competition with CDOM for irradiance, and their ability to photochemically generate ${ }^{\circ} \mathrm{OH}$ is consequently enhanced. Direct photolysis of pollutants is enhanced by outflow, because at equal water chemistry the bottom layers of a shallow water body are better illuminated than those of a deep one. Enhancement of direct photolysis would be higher for compounds that absorb sunlight in UV and most notably in the UVB region, because competition with CDOM for irradiance is more important in the UVB.

Evaporative water loss would modify very little the column-averaged $\left[{ }^{\bullet} \mathrm{OH}\right]$ and $\left[\mathrm{CO}_{3}{ }^{\bullet}\right]$, because the relevant formation and scavenging processes would be enhanced to the same extent and the two effects would compensate for each other. Also direct photolysis processes would not be modified by evaporative water loss, which would not change absorbance values or competition of solutes for irradiance. In contrast, water evaporation is expected to enhance processes mediated by ${ }^{3} \mathrm{CDOM}^{*}$ and ${ }^{1} \mathrm{O}_{2}$. A mixed scenario was also tested, where half water is lost by evaporation and half by outflow, which would favour ${ }^{3} \mathrm{CDOM}^{*}$ and ${ }^{1} \mathrm{O}_{2}$ more than ${ }^{\bullet} \mathrm{OH}$ and $\mathrm{CO}_{3}{ }^{-\bullet}$.

The ${ }^{\circ} \mathrm{OH}$ radical (the reactivity of which is enhanced by outflow) is less likely to produce harmful intermediates compared to ${ }^{1} \mathrm{O}_{2},{ }^{3} \mathrm{CDOM}^{*}$ or direct photolysis [19], but the fate of out-flown water and of its contaminants should also be taken into account. Drainage would probably spread water over a larger surface, with an overall enhancement of photochemistry because of reduced water depth. In contrast, seepage through soil into groundwater would exclude out-flown water from sunlight exposure, thereby stopping photochemical reactions. 
We acknowledge financial support from CNR - PNRA, MIUR - PRIN 2009 (project 20092C7KRC-ARCTICA) and University of Torino - EU Accelerating Grants, project TO_Call2_2012_0047 (Impact of radiation on the dynamics of dissolved organic matter in aquatic ecosystems - DOMNAMICS).

\section{References}

[1] M. Carere, R. Miniero, and M.R. Cicero, Trac - Trends Anal. Chem. 30, 1214 (2011).

[2] M. Goulden, D. Conway, and A. Persechino, Hydrol. Sci. J. 54, 805 (2009).

[3] A. Iglesias, L. Garrote, F. Flores, and M. Moneo, Water Resour. Manag. 21, 775 (2007).

[4] F. Ayache, J.R. Thompson, R.J. Flower, A. Boujarra, F. Rouatbi, and H. Makina, Hydrobiologia 622, 15 (2009).

[5] P.Q. Segui, A. Ribes, E. Martin, F. Habets, and J. Boe, J. Hydrol. 383, 111 (2010).

[6] M. Petrovic, A. Ginebreda, V. Acuna, R.J. Batalla, A. Elosegi, H. Guasch, M.L. de Alda, R. Marce, I. Munoz, A. Navarro-Ortega, E. Navarro, D. Vericat, S. Sabater, and D. Barceló, Trac Trends Anal. Chem. 30, 1269 (2011).

[7] C. Castaneda and M.A. Garcia-Vera, Hydrogeol. J. 16, 87 (2008).

[8] Y.M. Li, S.D. Arnold, C. Kozel, and S. Forster-Cox, J. Environ. Health 68, 10 (2005).

[9] E. Burri and M. Petitta, Irrig. Drain. 53, 287 (2004).

[10] M. Ricart, H. Guasch, D. Barceló, R. Brix, M.H. Conceicao, A. Geiszinger, M.J.L. de Alda, J.C. Lopez-Doval, I. Munoz, C. Postigo, A.M. Romani, M. Villagrasa, and S. Sabater, J. Hydrol. 383, 52 (2010).

[11] V. Osorio, S. Perez, A. Ginebreda, and D. Barceló, Environ. Sci. Pollut. Res. 19, 1013 (2012).

[12] I.M. Moreno, A. Avila, and M.A. Losada, Geomorphology 121, 305 (2010).

[13] S.T. Larned, T. Datry, D.B. Arscott, and K. Tockner, Freshw. Biol. 55, 717 (2010).

[14] J.V. Muller and U. Deil, Phytocoenologia 35, 327 (2005).

[15] A.L. Boreen, W.A. Arnold, and K. McNeill, Aquat. Sci. 65, 320 (2003).

[16] C. Richard, A. Ter Halle, M. Sarakha, P. Mazellier and J.M. Chovelon, Actual. Chim. 308, 71 (2007).

[17] S. Canonica, Chimia 61, 641 (2007).

[18] S. Canonica, T. Kohn, M. Mac, F.J. Real, J. Wirz, and U. Von Gunten, Environ. Sci. Technol. 39, 9182 (2005).

[19] A. Zertal, T. Sehili, and P. Boule, J. Photochem. Photobiol. A: Chem. 146, 37 (2001).

[20] S. Kebede, G. Admasu, and Y. Travi, Isot. Environ. Health Stud. 47, 71 (2011).

[21] S. Sanchez-Moral, S. Ordonez, D. Benavente, and M.A.G. del Cura, Sediment. Geol. 148, 221 (2002). 
[22] J.M. Ham, Trans. ASAE 42, 1303 (1999).

[23] M. Minella, M. Rogora, D. Vione, V. Maurino, and C. Minero, Sci. Total. Environ. 409, 3463 (2011).

[24] E. De Laurentiis, M. Minella, V. Maurino, C. Minero, G. Mailhot, M. Sarakha, M. Brigante, and D. Vione, Sci. Total Environ. 439, 299 (2012).

[25] S. Chiron, C. Minero, and D. Vione, Environ. Sci. Technol. 41, 3127 (2007).

[26] A.O. Aptula, T.I. Netzeva, I.V. Valkova, M.T.D. Cronin, T.W. Schultz, R. Kühne, and G. Schüürmann, Quant. Struct.-Act. Relat. 21, 12 (2002).

[27] A. Albinet, C. Minero, and D. Vione, Chemosphere 80, 759 (2010).

[28] D. Vione, G. Falletti, V. Maurino, C. Minero, E. Pelizzetti, M. Malandrino, R. Ajassa, R.I. Olariu, and C. Arsene, Environ. Sci. Technol. 40, 3775 (2006).

[29] J.E. Grebel, J.J. Pignatello, and W.A. Mitch, Environ. Sci. Technol. 44, 6822 (2010).

[30] B. Sur, M. Rolle, C. Minero, V. Maurino, D. Vione, M. Brigante, and G. Mailhot, Photochem. Photobiol. Sci. 10, 1817 (2011).

[31] S.E. Page, W.A. Arnold, and K. McNeill, Environ. Sci. Technol. 45, 2818 (2011).

[32] A.W. Vermilyea and B.M. Voelker, Environ. Sci. Technol. 43, 6927 (2009).

[33] G.V. Buxton, C.L. Greenstock, W.P. Helman and A.B. Ross, J. Phys. Chem. Ref. Data 17, 1027 (1988).

[34] S. Canonica, B. Hellrung, P. Muller, and J. Wirz, Environ. Sci. Technol. 40, 6636 (2006).

[35] S. Halladja, A. Ter Halle, J.P. Aguer, A. Boulkamh, and C. Richard, Environ. Sci. Technol. 41, 6066 (2007).

[36] S. Canonica and M. Freiburghaus, Environ. Sci. Technol. 35, 690 (2001).

[37] M.A.J. Rodgers and P.T. Snowden, J. Am. Chem. Soc. 104, 5541 (1982).

[38] P. Neta, R.E. Huie, and A.B. Ross, J. Phys. Chem. Ref. Data 17, 1027 (1988).

[39] S. Canonica, U. Jans, K. Stemmler and J. Hoigné, Environ. Sci. Technol. 29, 1822 (1995).

[40] D. Vione, R. Das, F. Rubertelli, V. Maurino, C. Minero, S. Barbati, and S. Chiron, Int. J. Environ. An. Chem. 90, 258 (2010).

[41] S. Loiselle, D. Vione, C. Minero, V. Maurino, A. Tognazzi, A. M. Dattilo, C. Rossi, and L. Bracchini, Wat. Res. 46, 3197 (2012).

[42] E. De Laurentiis, M. Minella, V. Maurino, C. Minero, M. Brigante, G. Mailhot, and D. Vione, Chemosphere 88, 1208 (2012).

[43] R.G. Zepp and D.M. Cline, Environ. Sci. Technol. 11, 359 (1977).

[44] Riccio, F., 2009. http://www.perseus.it.

[45] F. al Housari, D. Vione, S. Chiron, and S. Barbati, Photochem. Photobiol. Sci. 9, 78 (2010).

[46] B. Sur, E. De Laurentiis, M. Minella, V. Maurino, C. Minero, and D. Vione, Sci. Total Environ. 426, 3197 (2012).

[47] P.L. Brezonik and J. Fulkerson-Brekken, Environ. Sci. Technol. 32, 3004 (1998).

[48] E. De Laurentiis, S. Chiron, S. Kouras-Hadef, C. Richard. M. Minella, V. Maurino, C. Minero, and D. Vione, Environ. Sci. Technol. 46, 8164 (2012). 
[49] D. Vione, P. R. Maddigapu, E. De Laurentiis, M. Minella, M. Pazzi, V. Maurino, C. Minero, S. Kouras, and C. Richard, Wat. Res. 45, 6725 (2011).

[50] A. Tognazzi, A.M. Dattilo, L. Bracchini, C. Rossi, and D. Vione, Int. J. Environ. An. Chem. 92, 1679 (2012).

[51] P. R. Maddigapu, M. Minella, D. Vione, V. Maurino, and C. Minero, Environ. Sci. Technol. 45, 209 (2011).

[52] T. Jing, H. Xia, J.W. Niu, Y.S. Zhou, Q. Dai, Q.L. Hao, Y.K. Zhou and S.R. Mei, Biosens. Bioelectron. 26, 4450 (2011).

[53] A. Albinet, C. Minero, and D. Vione, Chemosphere 80, 753 (2010).

[54] R.M. Cory, J.B. Cotner, and K. McNeill, Environ. Sci. Technol. 43, 718 (2009).

[55] J. Wenk and S. Canonica, Environ. Sci. Technol. 46, 5455 (2012).

[56] J. Huang and S.A. Mabury, Chemosphere 41, 1775 (2000).

[57] D. Vione, V. Maurino, C. Minero, M.E. Carlotti, S. Chiron, and S. Barbati, C.R. Chimie 12, 865 (2009).

[58] L. Bracchini, S. Loiselle, A.M. Dattilo, S. Mazzuoli, A. Cozar and C. Rossi, Photochem. Photobiol. 80, 139 (2004).

[59] P. Warneck and C. Wurzinger, J. Phys. Chem. 92, 6278 (1988).

[60] M. Fischer and P. Warneck, J. Phys. Chem. 100, 18749 (1996).

[61] J.B. Wang, L.P. Zhu, Y. Wang, J.T. Ju, M.P. Xie, and G. Daut, J. Great Lakes Res. 36, 587 (2010).

[62] A.E. Martell, R.M. Smith, and R.J. Motekaitis, Critically selected stability constants of metal complexes database, Version 4.0 (1997).

[63] S. E. Braslavsky, Pure Appl. Chem. 79, 293 (2007).

[64] D. Vione, J. Feitosa-Felizzola, C. Minero, and S. Chiron, Wat. Res. 43, 1959 (2009). 
Table 1. Second-order reaction rate constants with ${ }^{\bullet} \mathrm{OH}, \mathrm{CO}_{3}{ }^{-\bullet},{ }^{1} \mathrm{O}_{2}$ and ${ }^{3} \mathrm{CDOM}^{*}$, and photolysis quantum yields of the pollutants considered in this work.

\begin{tabular}{|c|c|c|c|c|c|c|}
\hline & $k_{{ }_{O H}^{\prime}}^{\prime}, \mathrm{M}^{-1} \mathrm{~s}^{-1}$ & $k_{\mathrm{CO}_{3}^{-}}^{\prime}, \mathrm{M}^{-1} \mathrm{~s}^{-1}$ & $\begin{array}{c}k_{\mathrm{O}_{2}}^{\prime}, \mathrm{M}^{-1} \\
\mathrm{~s}^{-1}\end{array}$ & $\begin{array}{c}k_{{ }_{C D O M}^{*}}^{\prime}, \mathrm{M}^{-1} \\
\mathrm{~s}^{-1}\end{array}$ & $\Phi$ & Reference \\
\hline CBZ & $1.8 \cdot 10^{10}$ & Negligible & $1.9 \cdot 10^{5}$ & $7.0 \cdot 10^{8}$ & $7.8 \cdot 10^{-4}$ & [45] \\
\hline IBU & $1.0 \cdot 10^{10}$ & Negligible & $6.0 \cdot 10^{4}$ & $9.7 \cdot 10^{9}$ & 0.33 & [46] \\
\hline DCNP & $2.8 \cdot 10^{9}$ & Negligible & $3.7 \cdot 10^{9}$ & $1.36 \cdot 10^{8}$ & $4.5 \cdot 10^{-6}$ & [48] \\
\hline 24DNP & $2.3 \cdot 10^{9}$ & Negligible & Negligible & Negligible & $3.4 \cdot 10^{-5}$ & [50] \\
\hline
\end{tabular}



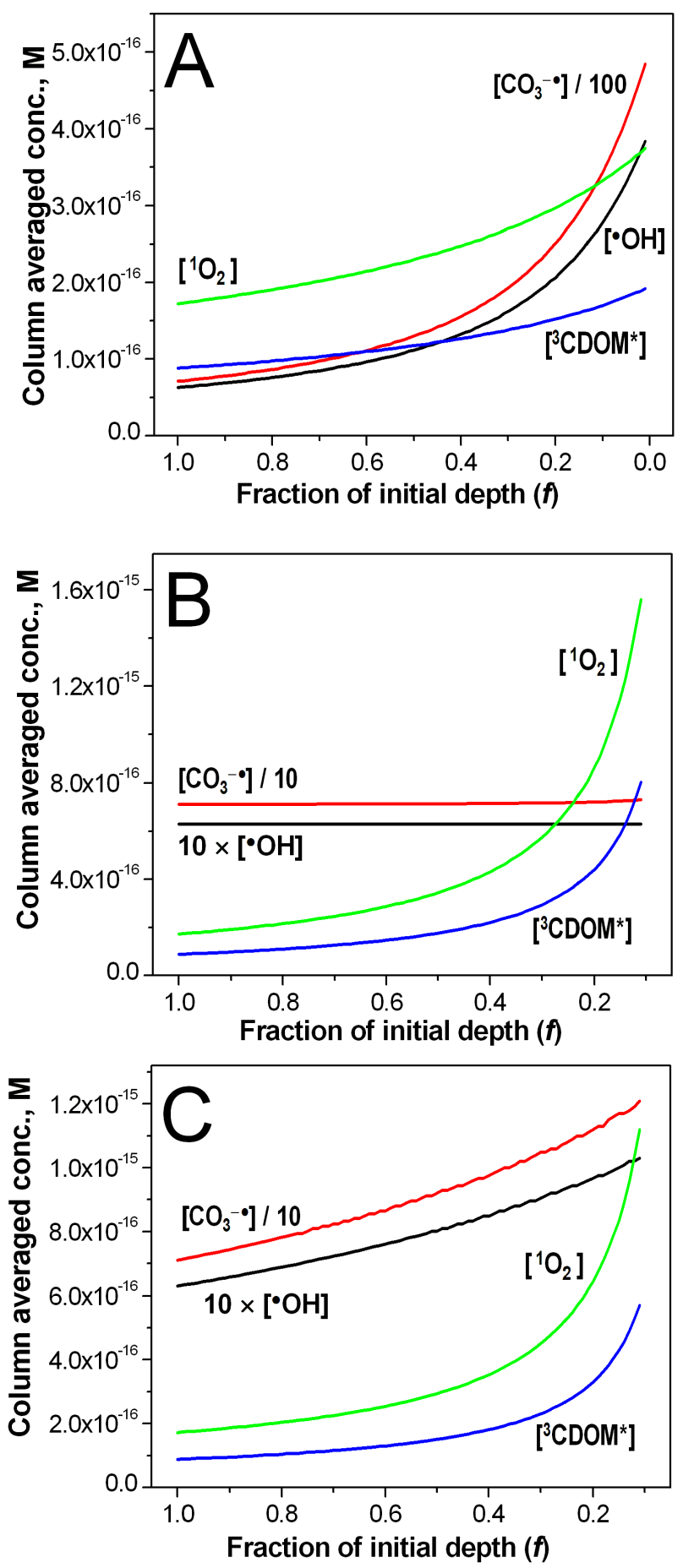

Figure 1. Modelled steady-state concentrations of ${ }^{\bullet} \mathrm{OH}, \mathrm{CO}_{3}{ }^{-\bullet},{ }^{1} \mathrm{O}_{2}$, and ${ }^{3} \mathrm{CDOM}^{*}$ (average values over the water column), as a function of the fraction $f$ of the initial depth $d_{\mathrm{o}}=10 \mathrm{~m}$. To plot all concentration values on the same $\mathrm{Y}$ axis, $\left[\mathrm{CO}_{3}{ }^{-}\right]$was divided by 10 or 100 and $\left[{ }^{\circ} \mathrm{OH}\right]$ was sometimes multiplied by 10 . Transient concentration values are referred to a sunlight UV irradiance of $22 \mathrm{~W} \mathrm{~m}^{-2}$. Three different scenarios of water loss are considered: outflow (a), evaporation (b) and a mixed one (c), where half water is lost by evaporation and half by seepage. Water chemical composition at $d_{\mathrm{o}}=10 \mathrm{~m}$ was as follows: $0.1 \mathrm{mM}$ nitrate, $1 \mu \mathrm{M}$ nitrite, $1 \mathrm{mg} \mathrm{C} \mathrm{L}^{-1} \mathrm{DOC}, 0.5 \mathrm{mM}$ bicarbonate, $10 \mu \mathrm{M}$ carbonate (water chemical composition: case A). Note that here and in all the following figures data are plotted against decreasing $f$, thus in the direction of increasing water loss. 


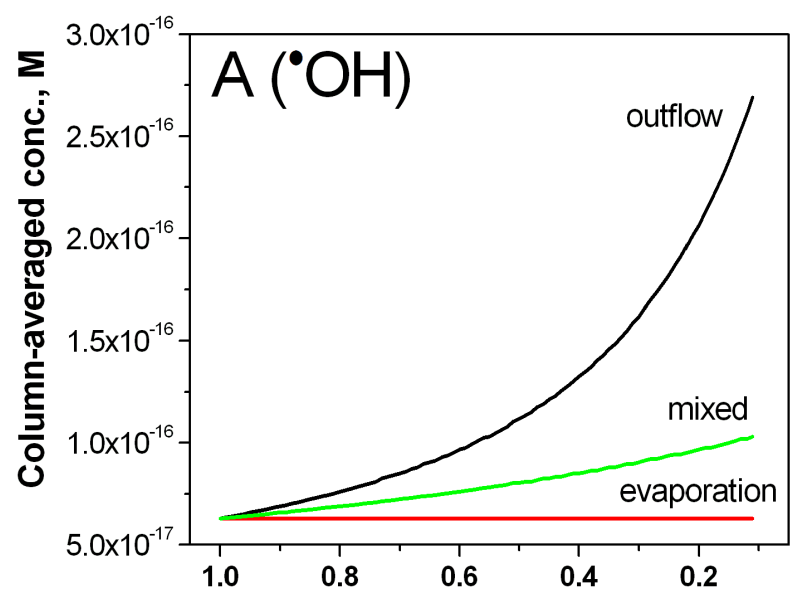

Fraction of initial depth $(f)$

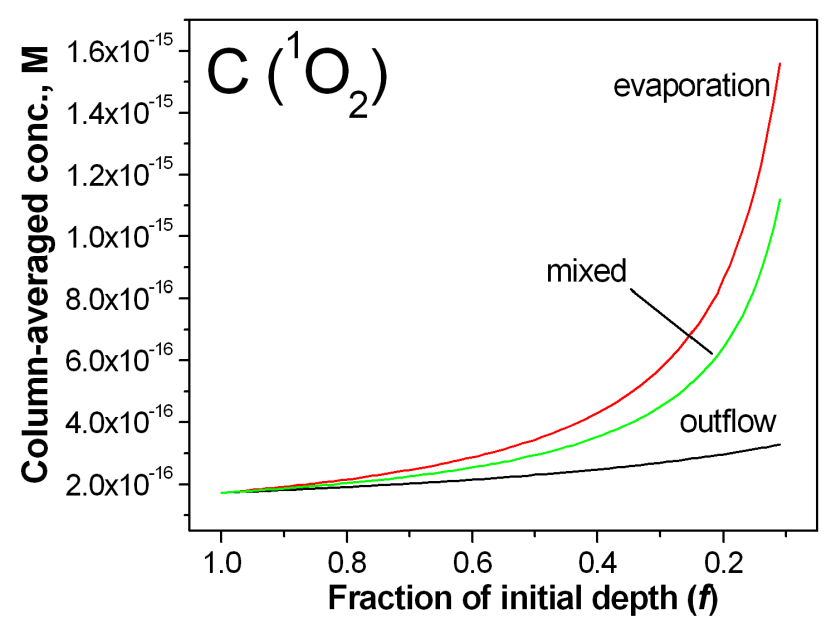

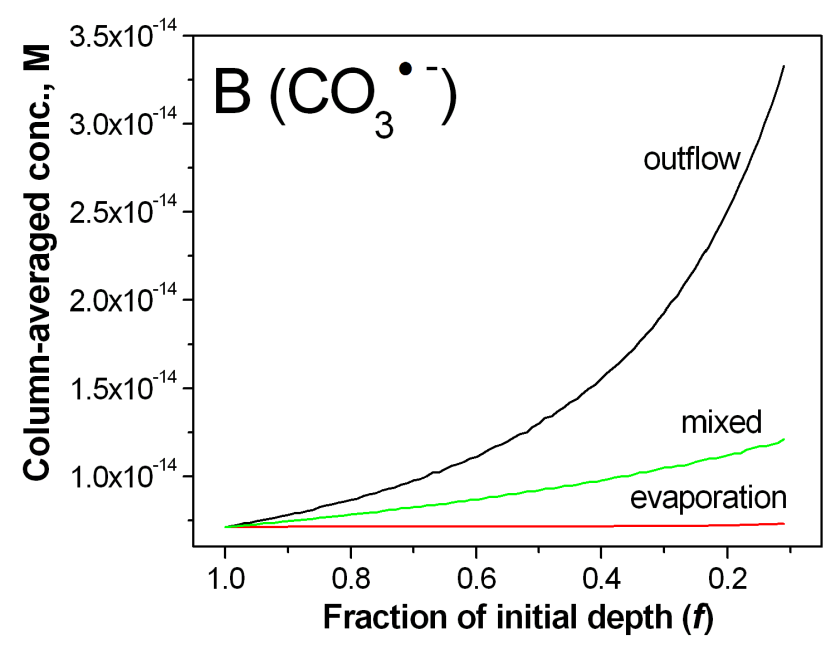

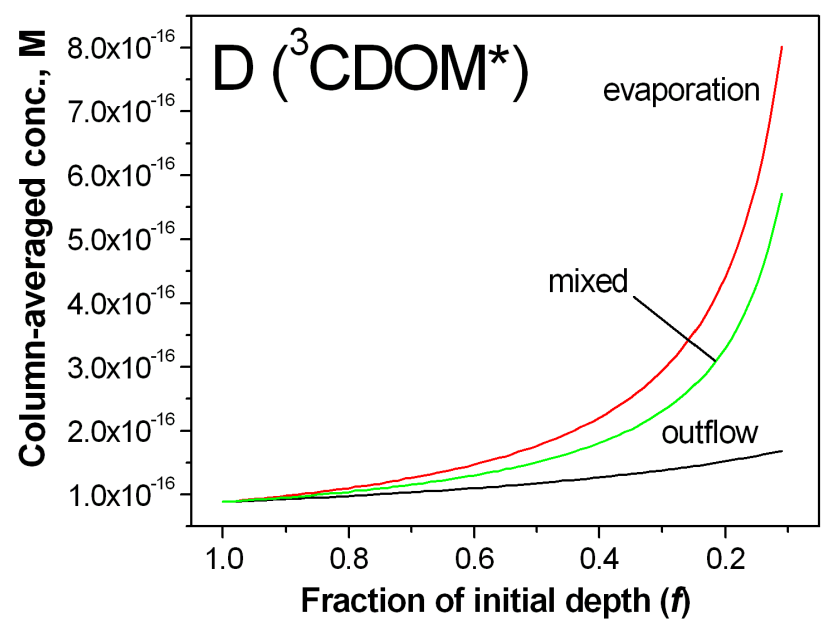

Figure 2. Modelled column-averaged steady-state concentrations of ${ }^{\bullet} \mathrm{OH}(2 \mathrm{a}), \mathrm{CO}_{3}{ }^{\bullet}(2 \mathrm{~b}),{ }^{1} \mathrm{O}_{2}(2 \mathrm{c})$, and ${ }^{3} \mathrm{CDOM}^{*}$ (2d), for the three different scenarios (outflow, evaporation, mixed), as a function of the fraction $f$ of the initial depth $d_{\mathrm{o}}=10 \mathrm{~m}$ (water chemical composition: case A). 

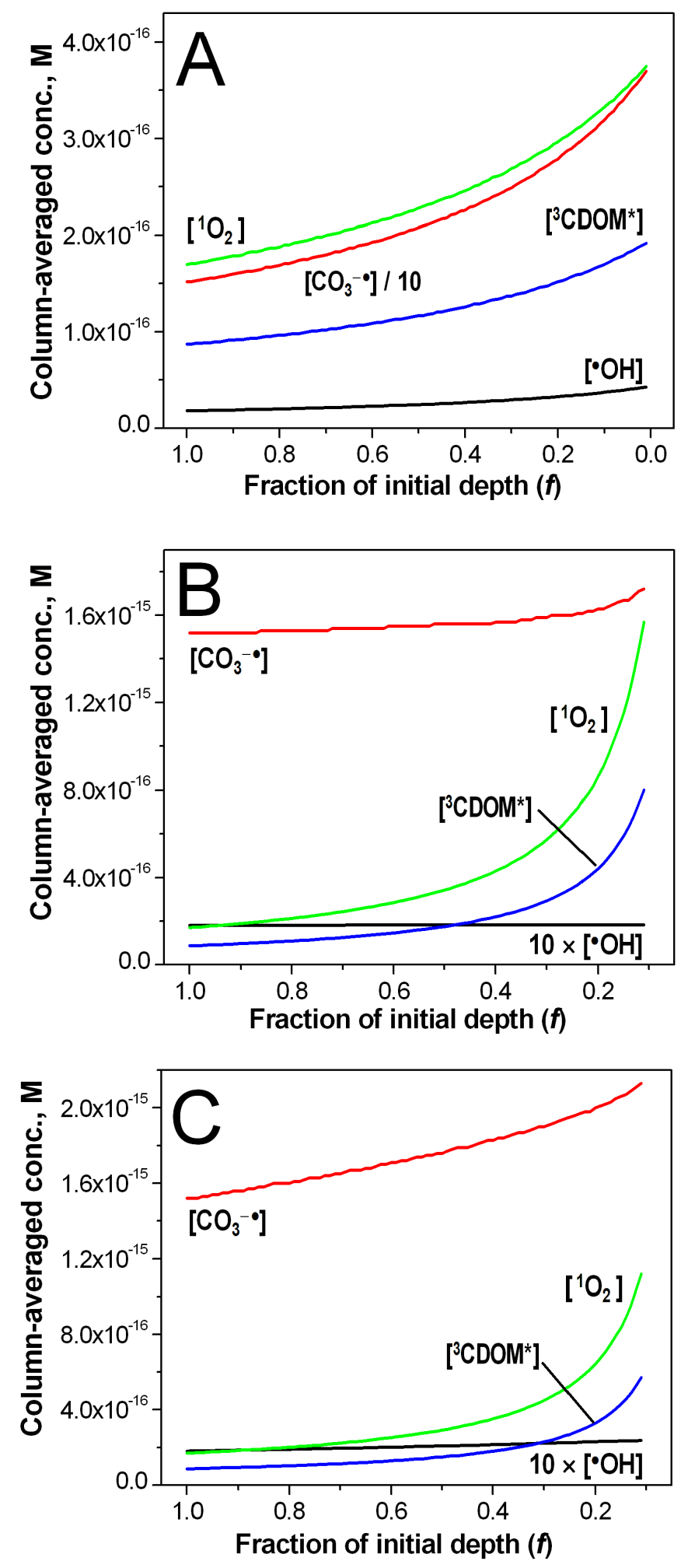

Figure 3. Modelled steady-state concentrations of ${ }^{\bullet} \mathrm{OH}, \mathrm{CO}_{3}{ }^{-\bullet},{ }^{1} \mathrm{O}_{2}$, and ${ }^{3} \mathrm{CDOM}^{*}$, as a function of the fraction $f$ of the initial depth $d_{\mathrm{o}}=10 \mathrm{~m}$. Note that $\left[\mathrm{CO}_{3}{ }^{-\bullet}\right]$ is sometimes divided and $\left[{ }^{\bullet} \mathrm{OH}\right]$ sometimes multiplied by 10 . Three water loss scenarios are considered: outflow (a), evaporation (b) and mixed (c). At $d_{\mathrm{o}}=10 \mathrm{~m}$ one has $1 \mu \mathrm{M}$ nitrate and $10 \mathrm{nM}$ nitrite (water chemical composition: case B). For all other conditions see Figure 1. 

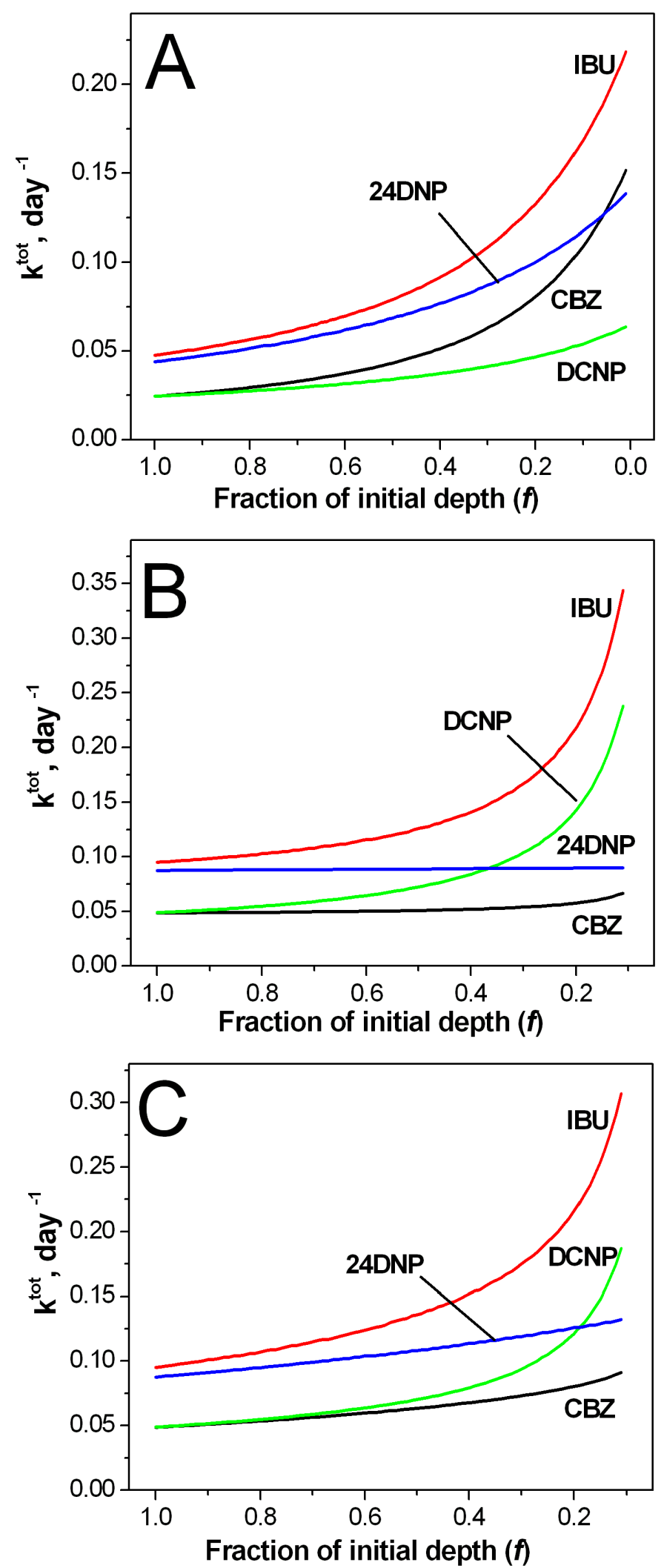

Figure 4. Modelled first-order transformation rate constants $\left(k^{\text {tot }}\right.$, day $\left.^{-1}\right)$ of CBZ, IBU, DCNP and 24DNP, as a function of $f$, in the three water loss scenarios of outflow (a), evaporation (b) and mixed (c). Water chemical composition at $d_{\mathrm{o}}=10 \mathrm{~m}$ : $0.1 \mathrm{mM}$ nitrate, $1 \mu \mathrm{M}$ nitrite, $1 \mathrm{mg} \mathrm{C} \mathrm{L}-1$ DOC, $0.5 \mathrm{mM}$ bicarbonate, $10 \mu \mathrm{M}$ carbonate (water chemical composition: case A). 

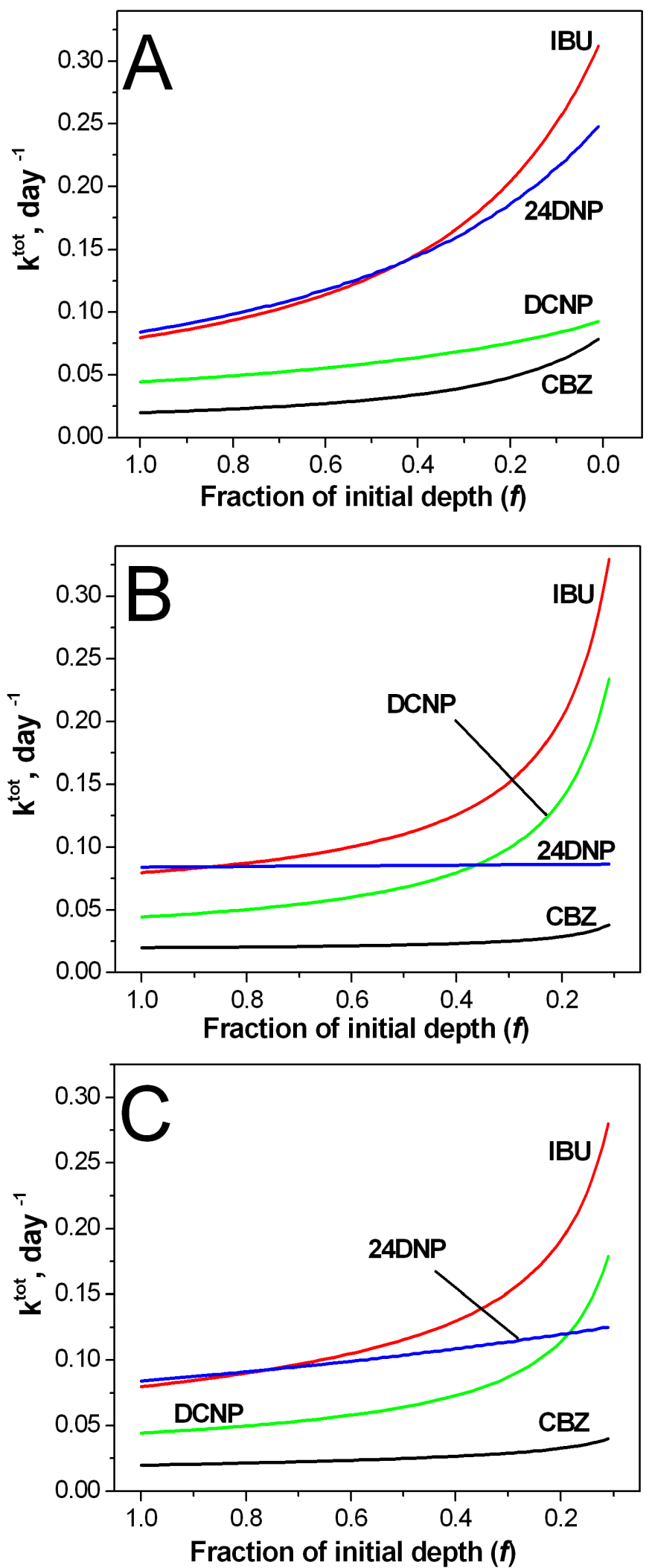

Figure 5. Modelled first-order transformation rate constants $\left(k^{\text {tot }}\right.$, day $\left.^{-1}\right)$ of CBZ, IBU, DCNP and 24DNP, as a function of $f$, in the three water loss scenarios of outflow (a), evaporation (b) and mixed (c). Water chemical composition at $d_{\mathrm{o}}=10 \mathrm{~m}: 1 \mu \mathrm{M}$ nitrate, $10 \mathrm{nM}$ nitrite, $1 \mathrm{mg} \mathrm{C} \mathrm{L}^{-1} \mathrm{DOC}_{\text {, }}$ $0.5 \mathrm{mM}$ bicarbonate, $10 \mu \mathrm{M}$ carbonate (water chemical composition: case $\mathrm{B}$ ). 